\title{
Preconceito e Discriminação: As Bases da Violência Contra a Mulher
}

Prejudice and Discrimination: The Bases of Violence Against Women

Prejuicio Y Discriminación: Los Fundamentos de La Violencia Contra La Mujer

Sergio Gomes da Silva

Universidade Federal do Rio de Janeiro

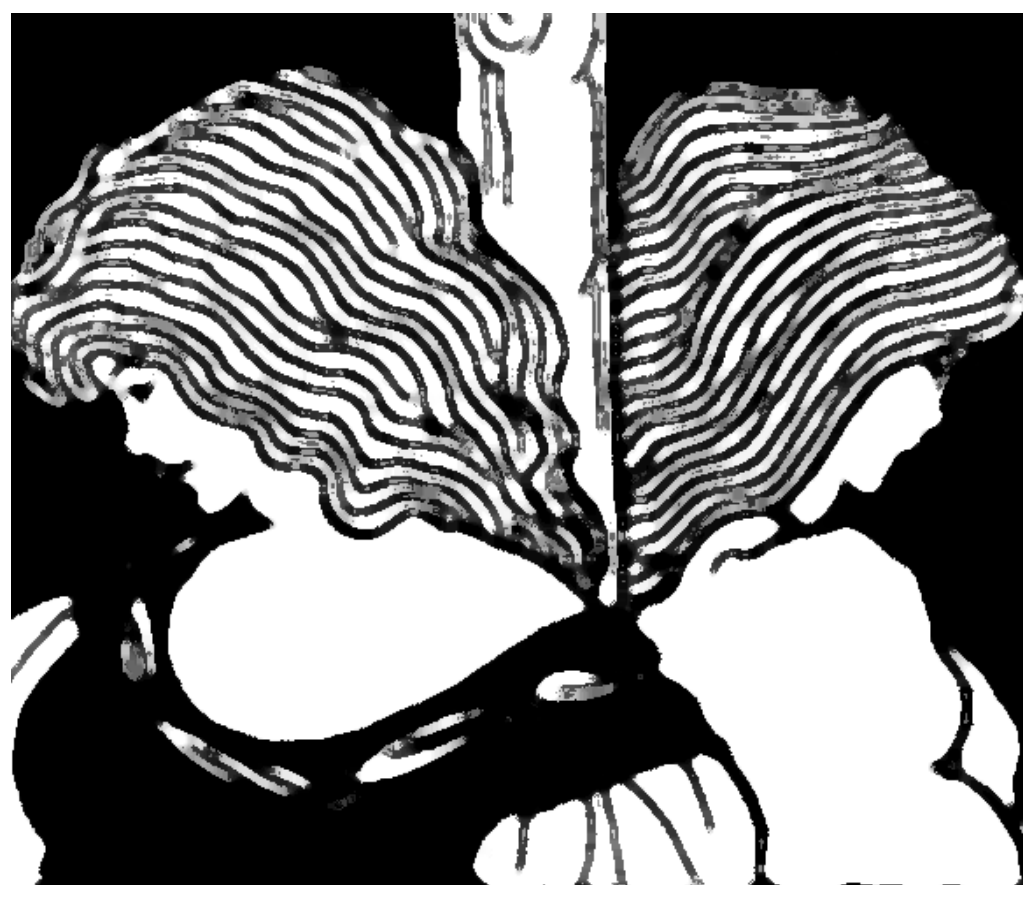


Resumo: A violência contra as mulheres não é rece̊nte na história da humanidade. Ela faz parte de um sistema sociohistórico que condicionou as mulheres a uma posição hierarquicamente inferior na escala de perfeição metafísica, produzindo um campo de força de relações assimétricas entre homens e mulheres em nossa sociedade. Assim sendo, o objetivo deste trabalho é analisar como o preconceito, a discriminação e a intolerância constituíram predicativos da violência de gênero, trazendo para essa discussão a interpenetração de três módulos distintos: sexo/gênero, raça/etnia e classe social. Apesar dos altos índices estatísticos de violência contra as mulheres em todo o mundo e dos avanços sociais, políticos e jurídicos no combate à violência, defende-se a ideia de que o movimento dos direitos humanos ainda precisa encontrar instrumentos efetivos na promulgação da cidadania e dos direitos das mulheres.

Palavras-chave: Preconceito. Discriminação. Violência. Direitos da mulher.

\begin{abstract}
Violence against women is not new in human history. It is part of a socio-historical system that ruled women a lower ranking in the scale of metaphysic perfection and produced strength of asymmetric relations between men and women in our society. Therefore, this study aims to analyze how prejudice, discrimination and intolerance are formed as a predicative of gender violence, bringing to this discussion the interpenetration of three separate aspects: sex/gender, race/ethnicity and social class. Despite the statistics of violence against women around the world and the social, political and legal advances in the fight against violence, we defend the necessity of human rights to find out effective instruments in the promulgation of citizenship and women rights.
\end{abstract}

Keywords: Prejudice. Discrimination. Violence. Women rights.

Resumen: La Violencia contra las mujeres no es reciente en la historia de la humanidad. Ella forma parte de un sistema socio-histórico que condicionó las mujeres a una posición jerárquicamente inferior en la escala de perfección metafísica, produciendo un campo de fuerza de relaciones asimétricas entre hombres y mujeres en nuestra sociedad. Siendo así, el objetivo de este trabajo es analizar cómo el prejuicio, la discriminación y la intolerancia constituyeron predicativos de la Violencia de género trayendo para esta discusión la interpenetración de tres módulos distintos: sexo/género, raza/etnia y clase social. A pesar de los altos índices estadísticos de Violencia contra las mujeres en todo el mundo y de los avances sociales, políticos y jurídicos en el combate a la Violencia, se defiende la idea de que el movimiento de los derechos humanos todavía necesita encontrar instrumentos efectivos en la promulgación de la ciudadanía y de los derechos de las mujeres.

Palabras clave: Prejuicio. Discriminación. Violencia. Derechos de la mujer.

A discussão acerca das desigualdades entre homens e mulheres, como sabemos, não é recente, muito pelo contrário: dos gregos antigos até bem pouco tempo atrás, acreditávamos que a mulher era um ser inferior na escala metafísica que dividia os seres humanos, e, por isso, os homens detinham o direito de exercer uma vida pública. Às mulheres, sempre foi reservado um lugar de menor destaque, seus direitos e seus deveres estavam sempre voltados para a criação dos filhos e os cuidados do lar, portanto, para a vida privada, e, durante o século das luzes, quem julgasse se apossar da igualdade estabelecida pela Revolução Francesa para galgar espaços na vida pública teria como destino a morte certa na guilhotina. Muitas mulheres que tentaram reivindicar seus direitos de cidadania tiveram esse destino.

Olympe de Gouges foi o mais perfeito exemplo de que a igualdade à qual os franceses se referiam era uma igualdade para bem poucos, para dizer a verdade, a igualdade era apenas destinada aos homens da classe burguesa. Olympe era escritora, feminista atuante e revolucionária na França nos tempos da Revolução, chegando a ter seu direito de fala silenciado ao publicar, em 1789, Os Direitos da Mulher e da Cidadã, no qual reivindicava a abolição do jugo masculino sobre o feminino. Resultado: em 
De acordo com Lasch (1999), a história das mulheres pode ser dividida em duas épocas, separadas pela revolução sexual na década de 60.
03 de novembro de 1793, a escritora foi guilhotinada, acusada de querer igualar-se ao homem, traindo a sua condição de mulher (Aragão, 2001). O mesmo ocorreu com a atriz Claire Lacombe, atriz da comédie française, líder popular e organizadora da Sociedade das Mulheres Revolucionárias.

Desse modo, percebemos que a igualdade alardeada por tal Revolução não se estendia às mulheres. Ela era de natureza jurídica, e não socioeconômica. Aliás, a revolução em nada permitiu ou contribuiu para um emparelhamento dos direitos legais, jurídicos, políticos ou sociais entre homens e mulheres. Como seria possível sustentar a hierarquia entre o homem e a mulher se o que estava em questão era justamente a igualdade de direito entre os cidadãos? Se homens e mulheres deveriam ser iguais diante da lei, deveriam ter acesso às mesmas posições sociais, e, se as mulheres tivessem acesso à mesma educação que os homens, elas poderiam ter acesso às mesmas posições que estes no espaço social.

Sabemos que a realidade conclamada pela Revolução Francesa não era essa. Pelo contrário, de acordo com Birman (2001), as consequências irrefutáveis da lógica da igualdade de direitos não se transformou em normas sociais que legitimassem a igualdade de condições entre os sexos e os gêneros. Foram necessários quase dois séculos para que as normas sociais resultantes da Revolução Francesa conferissem igualdade de direitos entre homens e mulheres, não tendo mais lugar o modelo do sexo único surgido na antiguidade greco-romana.

A concepção das diferenças entre os sexos marcada no corpo justificava, assim, as desigualdades políticas entre homens e mulheres, desigualdades essas que só viriam a diminuir com o advento da Declaração Universal dos Direitos do Homem e do Cidadão, de modo geral, e, mais especificamente, com as reivindicações dos movimentos de minorias sociais iniciados na década de 60, como, por exemplo, o movimento feminista.

De acordo com Lasch (1999), a história das mulheres pode ser dividida em duas épocas, separadas pela revolução sexual na década de 60. Daquela década em diante, as mulheres conquistaram grandes avanços no campo do trabalho, da política, da economia e no controle do seu próprio corpo, ensejados pelo movimento feminista, movimento social organizado a partir do Ocidente. Ao final do século XIX, na virada do século, passaram a ocorrer manifestações de discriminação contra a mulher. Dessa forma, o movimento voltado para a extensão do direito de voto das mulheres adquiriu visibilidade e maior expressividade (Louro, 1997).

Vamos nos deter um pouco mais sobre esse assunto. O movimento feminista e a revolução sexual, de fato, provocaram grandes transformações no mundo moderno no que se refere aos direitos e deveres das mulheres, conseguindo dar um grande salto na condição feminina nos três últimos séculos, seja no âmbito público, seja no privado. Corroborando nosso pensamento, Birman (2001) vai afirmar que, do direito de votar ao de poderem ser educadas, o percurso das mulheres foi marcado por um longo debate, com progressos e retrocessos. A década de 60, diz o autor, e as consequentes revoluções sociais e sexuais dela resultantes foram o divisor de águas de um longo processo de mudança cujos desdobramentos e consequências nos registros psicológicos, éticos e políticos ainda não temos condições de prever.

É o que podemos observar no tocante às identidades masculinas, femininas, homossexuais e heterossexuais, sem se reduzir meramente a estas, dada a multiplicidade das tipologias sexuais hoje vigentes. Mas, antes de prosseguirmos, 
verifiquemos rapidamente como o movimento feminista trouxe contribuições para a nossa sociedade.

De todos os movimentos sociais surgidos na segunda metade do século XX, o movimento feminista foi um dos que acarretou propostas de mudanças reais no tocante às diferenças entre homens e mulheres. Para Giddens (1993), o feminismo participa da modernidade de forma reflexiva, procurando assegurar os direitos de igualdade política e econômica e colocando em questão os elementos constitutivos das relações entre homens e mulheres, os quais estão intimamente vinculados aos processos de constituição de nossa identidade. $\mathrm{O}$ autor reconhece a contribuição do movimento feminista na modernidade, seja na política emancipatória, seja na política da vida, requisito fundamental para a construção da nossa autoidentidade.

Vale ressaltar que, de acordo com Silveira (1997), também podemos encontrar inúmeras outras contribuições propostas pelo movimento feminista. Isso ocorre, sobretudo, no movimento político-teórico, com suas contribuições para a proposição da perspectiva de gênero.

Segundo Silveira (1997), há uma intrínseca relação entre as contribuições teóricas para a perspectiva de gênero e a ascensão do discurso político fomentado pelo movimento feminista na segunda metade do século XX, relação essa corroborada pelo pensamento da socióloga norte-americana Joan Scott, que afirma que a presença das mulheres nas lutas sociais, ancoradas sobretudo na perspectiva de gênero, tem promovido um amplo conjunto de medidas no campo democrático-popular e produzido ações coletivas para a emancipação dos direitos femininos, mostrando que a desigualdade entre homens e mulheres é uma construção social e cultural das sociedades modernas, nas quais o destino biológico e anatômico subordinava as mulheres aos desígnios dos homens (Scott, 1990).

Ademais, o movimento feminista também proporcionou à sociedade moderna a compreensão que as mulheres não mais poderiam ser um grupo oprimido, sendo vítimas e sofrendo as consequências de pertencer a uma sociedade secularmente repressora, preconceituosa e discriminatória. Seria necessário, assim, recriar a relação com o gênero masculino.

Mas essa, como se sabe, não foi uma tarefa fácil. A violência contra a mulher viola os direitos humanos e se torna uma bandeira de luta não só para as mulheres mas também para todo aquele que compreende como universal a igualdade entre todos e o reconhecimento do outro como um de nós. Sabemos que essa violência está nos seus mais diferentes códigos, incrustada no pensamento estereotipado de homens e mulheres de uma sociedade herdeira de pensamentos caducos e de crenças esclerosadas, que compreendia a mulher como um ser inferior ao homem, daí, portanto, a violência física, o estupro, os assassinatos, o aborto indesejado, as torturas psicológicas e a mutilação genital, entre tantos outros atos de violência, sem falar na discriminação contra a condição feminina, principalmente quando o baixo nível social, econômico, as origens étnicas e raciais das mulheres vítimas de violência se coadunam com essas condições (Dimenstein, 1996). É por essa razão que enfatizamos que as desigualdades entre homens e mulheres não são tão recentes na história da humanidade e podem ser encontradas em quase todas as culturas no mundo.

O movimento feminista da década de 60 , ao propor uma discussão acerca do papel social da mulher no seio da sociedade, das relações familiares, das leis trabalhistas, das 
responsabilidades sexuais e reprodutivas, das políticas públicas e, principalmente, das relações interpessoais, deu origem a uma nova identidade feminina a partir da noção de gênero, e trouxe à tona um debate que era fomentado desde o século XVIII, com a cobrança e a legitimação dos direitos da mulher. Daí decorreram os estudos de gênero no âmbito acadêmico, que provocaram sucessíveis mudanças de comportamento e atitude na sociedade sobre o papel feminino e a luta pelos seus direitos, muito embora saibamos que vários entraves foram encontrados nesse percurso.

Sabemos, porém, que, na luta pela legitimação dos seus direitos neste início de século, muitas barreiras ainda precisam ser quebradas, muitos direitos precisam ser conquistados e muitas medidas preventivas e punitivas precisam ser levadas a cabo face às tristes estatísticas do estado de violência contra a mulher nos pequenos e grandes centros urbanos.

As estatísticas em torno dos altos índices de violência contra as mulheres em todo o mundo e, mais especificamente, no Brasil, não deixam dúvidas quanto à necessidade do combate sistematizado que deve ser feito bem como da necessidade de mudanças de comportamento e de atitudes da população frente à violência de gênero (Machado, 1998) e ao reconhecimento dos direitos da mulher. Bem sabemos como essas mudanças são lentas e como existem reais dificuldades em promovê-las.

\section{Mas como entender a violência de gênero nesse sentido?}

Do nosso ponto de vista, não compreendemos a violência contra as mulheres apenas como um ou vários atos sistematizados de agressão contra o seu corpo, seja da ordem do abuso sexual, seja do espancamento, da tortura física ou psicológica. No nosso entender, a violência que a mulher sofre está no seu dia a dia, incorporada e enraizada no imaginário social coletivo da nossa sociedade, de homens, mas também de mulheres, que legitimam a subordinação do sujeito feminino ao domínio do poder masculino. A violência contra as mulheres está velada no mascaramento e na subordinação da nossa linguagem cotidiana, no uso de expressões e de diversos jogos de linguagem, nas palavras de duplo sentido, na criação de referenciais para dar conta de uma realidade que não é a mais condizente com o seu papel na sociedade, também na criação de estereótipos que moldam formas singulares de preconceito e discriminação através de personagens da vida cotidiana, tais como a doméstica, a dona de casa, a professorinha, a mãe e a garota de programa estilo exportação, entre tantos outros tipos, cuja imagem se transformou em um objeto tão vendável quanto qualquer outro produto de consumo, com o corpo explorado através da mídia, além de servir às leis imperativas do comércio e do turismo sexual.

Quando um grupo social legitima papéis que não necessariamente condizem com a realidade desses mesmos atores sociais, cria um sistema de crenças que será disseminado no imaginário social coletivo. Esse sistema de crenças vai legitimar, por sua vez, a violência física ou sexual (também poderia legitimar qualquer outra), estabelecendo como norma a condição do homem como herdeiro único do sistema patriarcalista, machista e viril bem como do capitalismo selvagem do qual fazemos parte.

É contra esse sistema de crenças e contra essa forma de violência que o movimento feminista vai lutar, visto que a violência vai ser entendida além de simples agressão física ou sexual. Assim, de acordo com as nossas proposições, a violência de gênero pode ser entendida como uma decantação do preconceito, da discriminação e do sentimento de intolerância 
pelos quais as mulheres vêm passando nos últimos dois séculos.

No Brasil, os reflexos desse tipo de violência se encontram em toda a parte. Militantes dos direitos humanos, cientistas políticos e sociais têm trabalhado constantemente na investigação, na denúncia e na publicização dos altos índices de violência cometidas contra as mulheres pelos homens, tais como os crimes cometidos pela classe média e classe alta que mobilizaram a imprensa, mostrando a necessidade de se punir e erradicar a violência contra as mulheres nos primeiro anos da década de 70 .

O que isso quer dizer? De acordo com Mirian Grossi (como citado por Machado, 1998), "nos anos 70, no Brasil, a violência contra as mulheres não tinha visibilidade. Aliás, não existia essa expressão. Ela teve que ser nomeada, para que pudesse ser vista, falada e pensada" (p. 104).

Ora, para Lia Zanotta Machado, o feminino é morto pelo e em nome do masculino (Machado, 1998). As mulheres morriam em nome da honra masculina, em silêncio ou em segredo, às vezes devido a questões ligadas à sua vida privada ou à sua intimidade, o que fez com que o discurso dos movimentos sociais, tais como o movimento feminista, ganhasse respaldo através da publicidade dos atos de violência contra a mulher na mídia, sensibilizando a opinião pública ao mostrar aqueles que queriam ser reconhecidos como os não violentos ou refinados. Descobrimos que os civilizados da classe alta ou média, pertencentes à elite, eram tão violentos quanto os que pertenciam às classes populares, ou seja, a mídia fez a violência contra as mulheres vir a público, no início dos anos 70, expondo aquilo que já se sabia: a violência não tem classe, não se esconde sob as necessidades materiais de cada um, nem se distingue entre os sujeitos de maior poder aquisitivo ou entre aqueles que vivem no limite ou abaixo da linha de pobreza (Machado, 1998). De acordo com Organização Mundial de Saúde, a violência se tornou, desde a década de 90, um problema de saúde pública.

\section{Pré+ conceito e discriminação contra a mulher}

Durante anos, nossa sociedade construiu, em torno de si e no senso comum, um estereótipo relacionado ao sexo feminino, primeiro passo para a construção das bases do preconceito e da discriminação.

O estereótipo, na acepção de Marilena Chauí (1996/1997), vai referir-se, por um lado, a um "conjunto de crenças, valores, saberes, atitudes que julgamos naturais, transmitidos de geração em geração sem questionamentos, e nos dá a possibilidade de avaliar e julgar positiva ou negativamente 'coisas e seres humanos" (p. 116). Por outro lado, para a autora, o senso comum é a crença jamais questionada de que a realidade objetiva e subjetiva do mundo existe tal como nos é dada, cristalizando as ideias acerca do mundo, dos sujeitos e das ideias construídas histórica e socialmente ao longo do tempo.

Por muito tempo, a cristalização de muitos dos conceitos de que o direito deveria estar a serviço dos homens, denominados os mais fortes, serviram para construir falsas ideias e moldar muitos dos preconceitos contra o sexo feminino. Vale lembrar que as próprias mulheres participaram inequivocamente desses ideários construídos ao longo dos últimos três ou quatro séculos.

Assim sendo, partir da noção que meu semelhante merece mais privilégios porque pertence à classe dos incluídos parece ser uma falácia que se tem mantido até os dias 
atuais. Os estereótipos, os preconceitos e a discriminação contra as mulheres precisam ser analisados, estudados, pensados, repensados, proibidos, vigiados e punidos sob todas as formas, não obstante a diversidade multicultural em que vivemos até mesmo dentro de um mesmo país, e, acima de tudo, deve ser analisado o sentido irracional de se pensar que um ser humano possa ser humilhado e desprezado por razões de identidade de gênero. A esse sentimento de desconsideração e desmerecimento do outro ou da concepção de que esse outro, por algum motivo, possa ser alguém de menor valor e possuir menos direitos que eu chamamos de preconceito. Vejamos, então, como alguns autores o definem.

O preconceito pode ser encontrado nos mais diversos setores da sociedade. Assim, pode ter origem nos mais diversos modos, pode escolher suas vítimas e agir de modo violento e irracional sem que ao menos possamos nos dar conta.

A violência e a agressão contra mulheres, negros e homossexuais, até bem pouco tempo, eram práticas consideradas tão comuns que passavam despercebidas como formas de violência em nossa sociedade, onde os grupos oprimidos escondiam o seu sofrimento sem poder sequer denunciá-lo ou compreendê-lo. As mudanças de consciência na sociedade, se é que de fato existem dado o contingente de crimes cometidos contra esses atores sociais nos últimos anos - traduzem uma nova interpretação da realidade ora vigente.

Não foi por menos que muitos movimentos de minoria se formaram e se organizaram para reivindicarem seus direitos aos governantes. $\mathrm{O}$ problema do preconceito e da discriminação contra a mulher se torna, portanto, um problema de inclusão e de exclusão de indivíduos em uma dada sociedade. Os que não podem participar da grande maioria são colocados à margem, e, por isso mesmo, devem lá ficar e sofrer as consequências que Ihes são impostas pela chamada maioria (nesse caso, masculina).

É importante lembrar que a inclusão social foi neutralizada pelo valor negativo atribuído pela condição da diferença de cor, raça, sexo e classe, entre tantas outras diferenças, e marcou a sociedade brasileira durante séculos, o que resultou em uma sociedade hierarquizada, onde os vários segmentos das sociedades de massa não têm acesso nem a direitos nem a deveres como a grande maioria dos incluídos (Bandeira \& Batista, 2002) (não seria melhor denominá-los grande minoria?). Ora, somos regidos por um sistema de classes em que a maior parte da concentração de riquezas se encontra nas mãos de uma parcela muito pequena da população; porém, parece ser exatamente em prol dessa pequena grande maioria que as leis têm se voltado, ou seja, para dar, exatamente aos mais favorecidos, mais direitos e privilégios do que à grande minoria, portanto, à classe dos excluídos.

O sentido que damos a minoria não está unicamente restrito a uma composição demográfica, mas à forma como as "relações sociais, expressando valores, definem a distribuição de prestígio, legitimidade e poder que organizam os vínculos entre homens e mulheres, somados a outros critérios de classificação social" (Heilborn, 2000, p. 90). Não obstante, é necessário se entender o conceito de gênero como uma construção cultural, cuja teoria, elaborada nos últimos anos, é uma ramificação dos estudos culturais, ligados historicamente ao marxismo e à teoria social, que têm se sustentado, por sua vez, nas políticas de redistribuição e de reconhecimento, de acordo com os estudos empreendidos por Fraser (2001, 2007).

Parece até mesmo provável que tenhamos 
nos tornado uma sociedade regida por códigos de conduta, na acepção referida por Sennet (2001). Para esse autor, os códigos de conduta, apesar de darem maior flexibilidade às pessoas para moldar as suas vidas, também moldarão alguns hábitos e comportamentos disseminados pela sociedade, em uma nova ordem capitalista, imposta por mecanismos e estratégias de controle e submissão que trazem um consequente impacto no caráter dos indivíduos que já são vítimas do preconceito e da discriminação, conforme o que o autor denominou mecanismos sutis de violência.

Algumas dessas formas de violência estão encarnadas na conformação do próprio caráter do indivíduo, moldando formas de agir, pensar e sentir, comportar e lidar com o sujeito que está à nossa volta. Esses modelos de violência serão traduzidos em comportamentos de preconceito para com o nosso semelhante, construindo, assim, o pilar de toda discriminação e violência contra o sujeito contemporâneo. Não obstante essas formas particulares de ensejar o caráter e o comportamento do sujeito, o preconceito carrega em si mesmo sua própria etimologia.

\section{Segundo Alberto Dines,}

pré+conceito, o preaconceptu latino, é um julgamento prévio, sem ouvir as partes, posição irrefletida, pré+concebida, irracional. Também pode ser entendido como um pré+juízo, tanto que em espanhol se diz prejuício, em francês, é prejugé, em inglês, prejudice, e, em alemão, vorurteil. Em todos os casos, a mecânica etimológica é idêntica: o prefixo indicando antecipação e, o resto, significando julgamento.... Em português, o preconceito também significa dano, estrago, perda. Em outras palavras, a adoção sumária de uma opinião ou critério, antes de passar pelo filtro de um julgamento equânime, constitui um mal, ofensa moral. (Dines, 1996/1997, p. 46)

Já para Michel Taussig (1993) o preconceito vai referir-se a uma atitude interior (no sentido interno) de um sujeito que viola os atributos e os qualificativos em relação ao outro sujeito, estabelecendo o funcionamento cognitivo e os contactos perceptivos de forma equivocada, cindida e traumática, portanto, pondo sempre à prova (ou derrotando) as capacidade e os recursos simbólicos do outro. (citado por Bandeira \& Batista, 2002, p. 129)

A discriminação ocorre justamente quando essa atitude ou esse ato-pensamento cria uma distinção entre os outros ou sobre os outros; gera, então, um tratamento diferencial e, em consequência, um preconceito.

Alguns tipos de preconceito são tão rigidamente criados e difundidos nas sociedades de massa que começam a fazer parte da cultura de um povo através de estereótipos. A crença de que negro não é gente, negro não presta, índio é vagabundo, todo homossexual é efeminado e toda mulher loira é burra são exemplos disseminados em nossa cultura e estão tão enraizados no nosso imaginário que passam desapercebidos nas formas mais sutis de nosso discurso, de forma velada ou explícita.

O preconceito também pode estar vinculado à inclusão de um indivíduo em uma categoria, perfilando, assim, uma identidade grupal hegemônica a partir da atribuição de um conjunto de características negativas, fixas e imutáveis ao grupo. Assim, quanto mais um indivíduo se identifica com as características desse grupo, mais passa a fazer parte dele, vindo a sofrer as consequências pela sua inclusão no grupo discriminado.

Não obstante isso, o sistema de preconceito vai ser formado quando o senso comum se cristaliza no modo de pensar e de sentir de um grupo social. Desse modo, Marilena Chauí vai definir preconceito como "uma idéia anterior à formação de um conceito. $\mathrm{O}$ preconceito é a ideia preconcebida, anterior, portanto, ao trabalho de concepção ou 
conceitualização realizado pelo sentimento" (Chauí, 1996/1997, p. 117). Para a autora, o conceito é a ideia que se forma a partir do momento em que questionamos as coisas, estabelecendo critérios para perguntas e respostas e para as formas de conferir as respostas que foram oferecidas, ou seja, é um exercício de pensamento. O preconceito, ao contrário, é algo que não inclui o trabalho de pensamento, pois este organiza, reúne e sintetiza os dados imediatos da experiência. Enquanto o conceito é um trabalho intelectual e de pensamento que objetiva chegar a uma verdade, o preconceito parte da ideia de que ele é, em si, verdadeiro.

Não obstante, para Marilena Chauí, o preconceito possui quatro marcas significativas. A primeira delas é a familiaridade, ou seja, o preconceito exige que tudo seja familiar, próximo, compreensível e imediatamente transparente. Nesse caso, ele é inteiramente penetrado por nossas opiniões e indubitavelmente não tolera o complexo, o opaco, o ainda não compreendido. Nesse caso, o preconceito é julgado único, extraordinário, e está inserido no quadro de ideias e juízos preconcebidos, encarregados de dar sentido ao mundo visto, mas nunca dito ou pensado. Um exemplo disso está no preconceito contra aquilo que nunca foi visto antes; para muitos, a forma como a mídia tem transmitido a imagem dos palestinos, principalmente dos mulçumanos, tem provocado em muitos americanos o ódio irracional, disseminando o preconceito contra eles.

A segunda marca do preconceito, segundo Marilena Chauí, exprime sentimentos de medo, angústia, insegurança e conjura (ou esconjura) diante do desconhecido, transformando tais sentimentos em ideias certas sobre as coisas, os fatos e as pessoas, criando assim, estereótipos, isto é, modelos gerais de coisas, fatos e pessoas por meios dos quais se julga tudo quanto ainda não se havia visto. As ideias sobre o negro, o índio, a mulher loira e o homossexual, comentados anteriormente, servem de exemplo para a construção dos estereótipos.

A terceira marca é admirar o que não se compreende e, portanto, a propensão a reduzir o desconhecido ao já conhecido e indubitável, ou seja, o preconceito é um obstáculo ao conhecimento e à transformação, é conservador e ignorante. Não é à toa que muitos dos preconceitos perpetrados contra a mulher demoraram a ser derrubados e têm resquícios nos seus primórdios, como, por exemplo, a diferença nos salários das mulheres que compartilham empregos semelhantes aos dos homens ou a nadificação da sexualidade do gênero feminino.

E, por fim, o preconceito é intrinsecamente contraditório, ou seja, ama o velho e deseja o novo, confia nas aparências, mas teme que tudo o que reluz não seja ouro; teme a sexualidade, mas deseja a pornografia, afirma a igualdade entre os humanos, mas é racista e sexista. Segundo Marilena Chauí, o preconceito se julga senhor de uma realidade transparente que, na verdade, é opaca e oculta medos e angústias, dúvidas e incertezas.

É desse modo que a autora acredita que, dada a pluralidade de preconceitos das diferentes classes sociais, existe a substituição desses por um único preconceito, nesse sentido, por uma única ideologia (no entender de Marx), a da classe dominante, que tem gerado violência de toda espécie, entre elas, a violência contra os mais despossuídos, os mais pobres e os excluídos, como, por exemplo, as minorias étnicas, sociais e sexuais.

É importante também notar como o preconceito em relação às mulheres opera através da interpenetração dos eixos sexo/ 
gênero, raça/etnia, e classe social. Esses eixos fundamentam e constituem a base de toda organização social onde se dão as práticas de dominação, discriminação e preconceito, sendo a violência uma consequência direta da imbricação entre elas.

De acordo com Saffioti (1989), a acumulação capitalista tem influência decisiva na geração da miséria, e produz vítimas de toda sorte no que se refere à fome, à falta de moradia, de escolas e de saneamento básico, além da exposição da classe desfavorecida a doenças de toda sorte. Para essa autora, há três grandes sistemas de dominação e de exploração em nossa sociedade, quais sejam: (a) a desigual divisão das classes sociais; (b) o patriarcado e (c) o racismo, que são reforçadores do processo de vitimização a que mulheres, crianças e a parcela pobre da população estão submetidas, na medida em que o poder da sociedade capitalista ocidental é exercido predominantemente pelo homem branco e rico.

Logo, de acordo Saffioti, as categorias sociais subalternas no Brasil são essencialmente constituídas por mulheres, negros, pobres e crianças, nas quais, hierarquicamente, a mulher negra e pobre está em último lugar, e o homem branco rico e adulto está no topo, constituindo aquilo que a autora denominou a síndrome do pequeno poder. Essa síndrome é constituída de dispositivo de submissão dos hierarquicamente inferiores por aqueles que estão no topo da hierarquia social, determinado especificamente pelo seu lugar na divisão de classes e submetido às regras do poder econômico. Dito de outro modo, o pequeno poder se faz através da submissão do hierarquicamente inferior às regras impostas pelo seu superior, que obtém um prazer nevrálgico com essa prática hedionda na qual o poder é exercido, permitindo a perpetuação do status quo do homem, branco, rico e adulto, não obstante as mudanças sociais e culturais que as mulheres produziram nas últimas duas décadas no campo profissional, social, político e econômico. É nessa frente de batalha que os movimentos dos direitos das mulheres vêm lutando na última década, forçando a produção de políticas públicas para a garantia de seus direitos.

Isso pode ser visto com a publicação do relatório Por Trás do Silêncio - Experiências de Mulheres com a Violência Urbana no Brasil, lançado pela Anistia Internacional (2009), que expôs os padrões de violação dos direitos humanos de mulheres em seis Estados da União - Bahia, Sergipe, Pernambuco, Rio de Janeiro, São Paulo e Rio Grande do Sul. Nesse relatório, por meio da história dessas mulheres, observamos como os altos índices de violência se coadunam com a ausência de proteção do Estado às mulheres em estado de vulnerabilidade, à criminalidade e ao seu pertencimento à classe social, sobretudo no que diz respeito ao tráfico de drogas nos pequenos e grandes centros urbanos.

O relatório também revela como as mulheres moradoras de comunidades socialmente excluídas batalham diariamente para (sobre) viver, educar os filhos e lutar por justiça nas favelas, ao passo que sofrem risco de vida e estão sujeitas aos ditames do crime organizado, servindo no mais das vezes de moeda de troca entre facções rivais, de mulas para o tráfico de drogas ou submetidas ao poder corrupto da polícia, que deveria protegê-las. Nessas comunidades, dificilmente haveria possibilidade de levar a cabo as determinações da Lei Maria da Penha, considerada, por grande parte dos movimentos sociais, um dos maiores avanços no sistema legislativo brasileiro, reforçado por vários relatórios de organizações governamentais e não governamentais publicados após a sua promulgação.

De acordo com o Relatório Global do Fundo de Desenvolvimento da ONU para a Mulher (Unifem, 2009) a Lei Maria da Penha (Lei no 11.340/06), promulgada pelo presidente Luiz Inácio Lula da Silva em agosto de 2006, é uma das três leis mais avançadas no mundo para o 
enfrentamento da violência contra as mulheres. O relatório afirma que a legislação brasileira tem avançado nesse sentido e se colocado ao lado da Lei de Proteção contra a Violência de Gênero na Espanha, promulgada em 2004, muito embora o Estado tenha dificuldade para aplicar a Lei no11.340/06. Entre as mudanças na legislação com a Lei Maria da Penha, está o aumento do rigor das punições contra as agressões sofridas pelas mulheres no âmbito doméstico ou familiar. Não obstante, o relatório aponta também alguns desafios que precisam ser superados, tais como maior participação das mulheres nos espaços de poder e decisão, garantia de políticas publicas que assegurem seus direitos e responsabilização do poder público em relação às políticas que as contemplam, bem como sua maior participação na esfera pública e privada, tal qual referido pelo II Plano Nacional de Políticas para as Mulheres (Secretaria Especial de Políticas para as Mulheres, 2008). É inegável que a presença das mulheres nos movimentos sociais trouxe questionamentos a respeito das rígidas separações dicotômicas entre binômio público e privado, razão e emoção, subjetividade e objetividade, real e utópico, igualdade e diferença, masculino e feminino, poder e saber, entre tantas outras, trazendo para a cena pública debates que passaram a figurar na agenda política no cenário nacional e internacional.

Parece inegável, então, que as questões de gênero iniciadas com os questionamentos dos movimentos sociais em geral e o do movimento feminista, em particular, sempre estiveram perpassando a construção das políticas de afirmação identitária e o fomento das políticas públicas e de cidadania. É interessante notar como esse amplo debate provocou mudanças de atitudes e comportamentos nas sociedades modernas, como forçou também uma mudança nas políticas públicas e de cidadania para garantir às mulheres a parte que Ihes cabia nessa sociedade. Porém, faço coro com Mirian Adelman quando esta promove alguns questionamentos para entender como isso se deu, sobretudo, quando incluímos nesse discurso a questão das sexualidades marginalizadas:

Como entender a construção histórica de
sexualidades marginalizadas, de pessoas
e grupos que são oprimidos pela maneira
que vivem sua sexualidade? O que isso diz
de específico sobre a sociedade ocidental
moderna (e o mais importante), como e
por que surgem, na segunda metade deste
século, movimentos sociais e políticos
articulados a partir da identidade sexual
(e nós acrescentaríamos, da identidade de
gênero)? Qual a relação desses movimentos
com os outros novos movimentos sociais
do mesmo momento histórico? (Adelman,
2000, p. 164)

Bandeira e Batista (2002) talvez nos apresentem uma possível resposta. Segundo essas autoras, as diversas manifestações de afirmações identitárias, tais como o orgulho de ser negro, homossexual, mulher e indígena, entre outras, denunciavam a existência de preconceito, de discriminação e de exclusão nas várias esferas da sociedade. Os movimentos sociais surgiram para denunciar esses modelos discriminatórios, pondo a nu a presença inquietante da violência nas relações sociais desses atores sociais discriminados e vítimas de todo tipo de violência.

É importante lembrar alguns questionamentos possíveis de se fazer ao se seguir essa linha de pensamento acerca da emancipação das políticas identitárias, pois, como Perlongher (1993), "fala-se de 'identidade negra', 'identidade feminina', 'identidade homossexual', mas, muito mais raramente, de uma 'identidade branca, ocidental, heterossexual e masculina'. É como se o dispositivo de identidade servisse para os dominadores reconhecerem e classificarem os dominados" (p. 138). De fato, esta parece uma verdade inquestionável: as discussões acerca dos direitos das minorias só existem porque uma pequena maioria faz uso delas, servindo-se de políticas públicas para todos 
aqueles que estão no grupo dos excluídos (sociais, étnicos, sexuais, econômicos, entre tantos outros).

O pilar sobre o qual se sedimentava o discurso dos direitos da mulher pautava-se fundamentalmente em um discurso sobre e necessidade emergente de diminuir a diferença entre os sexos, a garantia de igualdade de direitos sobre todos os aspectos e, principalmente, a possibilidade de exercer a plena cidadania, com todos os direitos humanos essenciais à vida de um indivíduo. Podemos entender o preconceito, assim, como gerador da discriminação e da desigualdade que exclui o indivíduo da chamada ética da igualdade ou de reciprocidade, na qual estão fundados o preconceito e a discriminação.

Desse modo, também podemos entender o preconceito como algo usualmente incorporado e acreditado. Ele é a mola central e o reprodutor mais eficaz da discriminação e da exclusão em que o sujeito pode estar susceptível, e gera a violência a que nos referimos anteriormente e o estigma a que vai ficar atrelado.

O preconceito, então, vai sendo introduzido na vida cotidiana nos mais diversos modos e da forma mais disfarçada possível, associando-se a certos tipos de ocupação exercida pela mulher, circulando através de certas imagens e representações. O exemplo disseminado pela mídia é mais do que suficiente ao ensejar no imaginário social coletivo a imagem da mulher como produto de consumo, devendo fazer com que nos mantenhamos alerta no combate ao desrespeito à imagem do papel feminino quando este está a serviço da violação dos direitos humanos.

O preconceito contra as mulheres deve ser moralmente condenado e a discriminação juridicamente sujeita à punição legal, pois este pode se encontrar não só disseminado nas mentes coletivas de nossa sociedade como se manifestar de forma mais sutil, disfarçada, através dos nossos hábitos linguísticos e comportamentos e atitudes, dificultando a reunião de provas com validade jurídica (Bandeira \& Batista, 2002).

É o caso, por exemplo, das violências psicológicas a que algumas mulheres estão sujeitas devido ao estigma que carregam na sociedade contemporânea. Vários desses preconceitos podem estar presentes em um mesmo grupo de indivíduos, no qual o imaginário social coletivo tenha tomado esses valores como norma, difundindo-a através da cultura.

Quando o estigma passa a fazer parte do cotidiano de um dado grupo e de uma dada identidade social ou cultural, e quando, já formado, ele se cristaliza nas mentes de uma dada comunidade ou sociedade de massa, passa a gerar nessa mesma comunidade e sociedade um sentimento que se tornou mote para as grandes atrocidades cometidas contra o ser humano ao longo do século XX, qual seja, o sentimento de intolerância. Combatêlo deve ser o princípio básico inerente a todo aquele que se propõe a lutar em favor dos direitos e da dignidade humana.

\section{Alguns dados sobre a violência de gênero no Brasil}

As estatísticas sobre a violência contra as mulheres não mentem. Elas fazem parte da mobilização de órgãos públicos e privados para demonstrar os índices de violência de gênero no Brasil e no mundo. A partir desses dados é que os governos passam a se mobilizar em prol de políticas públicas na garantia de direitos e deveres das mulheres. Vejamos alguns desses dados.

De acordo com Souza e Adesse (2005), o Ministério da Saúde reconhece que menos de $10 \%$ dos casos de violência sexual são 
notificados nas delegacias especiais de mulheres. Apesar dos altos índices de estupro notificados, é reconhecido que eles são certamente subnotificados.

Entre 2003-2004, um estudo sobre violência doméstica e sexual e sua repercussão na saúde da mulher foi concluído pelo Departamento de Medicina Preventiva da Faculdade de Medicina da USP, em parceria com o Coletivo Feminista Sexualidade e Saúde e o SOS Corpo, Gênero e Cidadania, de Pernambuco, sob orientação da OMS (Organização Mundial da Saúde). Essa pesquisa foi realizada em oito países, contando com 4.299 visitas domiciliares na cidade de São Paulo e na Zona da Mata pernambucana, e entrevistou 2.645 mulheres de 15 a 49 anos. Dentre as entrevistadas, 27\% afirmaram terem sido vítimas de violência por parceiros ou ex-parceiros em São Paulo e 34\%, na Zona da Mata, em Pernambuco. A região que tem apresentado maior incidência de estupro no Brasil ainda é a Região Sudeste, talvez por apresentar grande concentração populacional nos centros urbanos ou por ser porta de entrada para o turismo sexual no Brasil (Souza \& Adesse, 2005).

Não obstante, de acordo com Portella (2006), em 2003, no Estado de Pernambuco, ocorreu o assassinato de 300 mulheres, e 12 mil queixas foram registradas nas delegacias das mulheres, segundo a Secretaria de Defesa Social de Pernambuco, sendo a maioria na região metropolitana da cidade do Recife, dos quais $90 \%$ eram pobres. Apesar de esses índices se referirem apenas a duas metrópoles urbanas como representantes da realidade brasileira e de esses índices terem diminuído na atualidade, os maustratos e os abusos cometidos contra mulheres ainda são significativos: em 2004, para cada 5 mulheres, uma já sofreu algum tipo de violência sexual, sendo que a violência familiar aparece entre mulheres dos 15 aos 45 anos de idade (Gomes, Minayo, \& Silva, 2005).

Esses dados não podem ser desprezados.
O fato de a violência doméstica ou familiar parecer ter diminuído não explica os diversos casos de estupro mantidos nas estatísticas de banco de dados de ONGS e nas delegacias especiais de mulheres, além de estarem refletidos nos relatórios das Secretarias de Segurança Pública. Acrescente-se a isso o incentivo público para coibir atos de violência e agressão contra mulheres em todo o País, que foi retratado até mesmo em folhetins televisivos ou em campanhas publicitárias e ganhou destaque na mídia. De modo geral, ainda há muito trabalho a ser feito.

Tomemos o caso exemplar da cidade do Rio de Janeiro. Considerada um grande centro urbano onde a violência é predicativa da vida diária da população de todas as classes sociais, o caso se torna mais agravante quando consideramos a população de baixa renda. O Dossiê Mulher, lançado pelo Instituto de Segurança Pública do Governo do Estado do Rio de Janeiro, em 2009, mostra amplamente o mapa da violência urbana nessa cidade, sobretudo no que diz respeito à violência contra as mulheres. Nesse dossiê, os casos de atentado violento ao pudor, de ameaça proveniente de violência doméstica ou familiar, de estupro ou de homicídio permaneceram tão altos quanto no final da década passada.

Segundo as estatísticas do Dossiê Mulher, só no Estado do Rio de Janeiro, em 2008, o percentual de mulheres vítimas de ameaça foi de $67,4 \%$, dos quais as vítimas tinham entre 25 a 44 anos. Desse percentual, 49,5\% foi classificada como de cor branca e solteira. No mesmo ano, das 21.616 vítimas de ameaça doméstica ou familiar, 93,5\% eram mulheres, e apenas 2,4\% eram homens, o que prova que as mulheres continuam sendo as maiores vítimas de lesão corporal dolosa nesse Estado. O ano 2008 também registrou 41.458 ameaças de agressão contra mulheres nas delegacias especiais, o que dá, aproximadamente, 113 vítimas por dia em todo o Estado do Rio de Janeiro, sendo que 48,4\% tinham como provável autor o companheiro ou ex-companheiro, o que reforça a síndrome do pequeno poder defendida por Saffioti (1989). 
É importante ressaltar que, por trás de cada notícia veiculada no jornal ou na televisão, há uma história de vida marcada eminentemente pelo sofrimento e pela dor de estar subjugada a um destino corporal, sexual, cultural e social; mais do que isso: a violência contra as mulheres cada vez mais vem se afirmando em nossa sociedade como uma questão de saúde pública e se torna uma das metas do governo brasileiro nos últimos anos.

Em 2007, por exemplo, o Governo Federal lançou o Pacto Nacional pelo Enfrentamento à Violência Contra as Mulheres. O objetivo do governo, com esse pacto, foi assegurar a efetividade de políticas públicas para a redução das desigualdades sociais e regionais, promovendo a igualdade de gênero, raça, etnia e classe social, no controle rigoroso de uma estabilidade fiscal e de preços de produtos em geral, ou seja, a sustentabilidade da economia financeira do País (Brasil, 2007), malgrado a crise econômica que se instalou em todo o mundo desde o final de 2008, sobretudo nos Estados Unidos e na Europa.

O Pacto Nacional, desse modo, objetiva reduzir os índices de violência contra as mulheres e promover mudança cultural a partir da disseminação das atitudes igualitárias e de valores éticos; pretende também garantir e proteger os direitos das mulheres em situação de violência, em especial os das mulheres negras, indígenas, trabalhadoras do campo e os daquelas que estão no limite ou abaixo da linha de pobreza, fortalecendo o empenho de implementação e de efetivação da Lei Maria da Penha, os direitos sexuais e reprodutivos (malgrado a feminilização da AIDS e dos altos índices de gravidez na adolescência), o combate à exploração sexual e o tráfico de mulheres e, por fim, a promoção da cidadania das mulheres em situação de prisão através da reintrodução desse contingente no mercado de trabalho. Nenhuma dessas ações, contudo, pode ser efetivamente levada a cabo sem uma ampla reestruturação do governo para diminuir os altos índices da linha de pobreza, com a garantia de uma educação de qualidade, de habitação, de saneamento básico, de planejamento da saúde e de emprego para essa parcela da população. Quando sujeitos adquirem dignidade a partir da sua força de trabalho, podem voltar a se sentir tanto sujeitos de direitos quanto sujeitos de deveres.

\section{Considerações finais}

A década de 90, assim, marcou um processo de expansão dos direitos humanos, caracterizando intensa mobilização internacional, com o envolvimento de governos e de organizações da sociedade civil, entre outros grupos, fazendo com que se reconhecesse o caráter político dos instrumentos na garantia dos direitos humanos, cujo conteúdo expressa o jogo de alianças, tensões e embates no cenário nacional e internacional (Pitanguy, 2003).

No caso do Brasil, um bom exemplo desse processo é encontrado na Constituição de 1988, que trouxe em seu texto um conjunto de ações e garantias afirmativas para a promoção dos direitos da mulher (apesar de sua eficácia e efetividade serem criticáveis), do Programa Nacional de Direitos Humanos, de 1996 (revisado no ano 2002), e do Pacto Nacional pelo Enfrentamento à Violência Contra as Mulheres, de 2007, documentos que colocavam explicitamente as mulheres na própria definição dos direitos humanos e propunham a afirmação dos direitos das minorias identitárias (Figueiredo, 1999).

Não é incomum, portanto, encontrarmos, nos dias atuais, grande preocupação por parte da sociedade com a constituição de identidades masculinas e femininas e com a problemática do sexo e do gênero. É interessante indagar, porém, como essas identidades podem se situar no mundo contemporâneo sem grandes conflitos identitários e sem grandes sofrimentos psíquicos por pertencer a essa ou a aquela identidade de gênero ou de sexo. $\mathrm{O}$ que podemos observar, ao longo dos últimos 
anos, é que minorias sexuais ou de gênero têm sofrido mais do que aqueles que pertencem à grande parcela dos incluídos no mesmo mundo patriarcalista, machista, capitalista, neoliberal e globalizado, cujo indivíduo se encerra cada vez mais em si mesmo, mantendo um culto ao individualismo e não encontrando outra saída a não ser infringir nos mais fracos o seu poder, mantido a ferro e a fogo ao longo da História.

Vítimas durante um longo período histórico, o que restava às mulheres senão lutarem pelos seus direitos, colocando a questão de gênero frente às suas reivindicações como minoria social? Foi a partir das reivindicações do movimento feminista e da própria sociedade civil, do direito ao voto, das garantias trabalhistas, da denúncia da opressão e da estrutura de classes, primando pela igualdade de direitos entre homens e mulheres, que governos de todo o mundo se reuniram, discutiram, avaliaram, analisaram os questionamentos e estabeleceram mecanismos internacionais em defesa dos direitos da mulher.

A busca por um ideal de solidariedade humana, a luta contra as discriminações e os preconceitos muito bem arraigados em nossa cultura e, principalmente, o desejo de uma sociedade mais tolerante, mais justa, menos violenta e eticamente possível é a crença absoluta de uma sociedade e de um grupo de pessoas que acreditam que vale a pena lutar por algumas utopias, pois elas se tornam ainda necessárias em um mundo onde o diferente nos é tão insuportavelmente estranho que passa a valer menos em relação a direitos ou deveres. A criação, portanto, de uma sociedade mais tolerante é também a criação de uma sociedade mais ética ao admitirmos ou reconhecermos o Outro como se fosse um de nós, ou seja, ao passarmos a tolerar mais aquele que nos é semelhante.

Compreendemos, pois, que a luta pelos direitos humanos e contra a violência, o preconceito e a discriminação, não só contra as mulheres, mas contra todos aqueles que são vítimas, deve ser encarado como um mal a ser combatido, vigiado, punido e disciplinado.

É na crença de mudanças sociais, no engajamento ou não da militância dos direitos humanos por grupos sociais concebidos como minorias (negros, mulheres, trabalhadores rurais, sem terra, sem teto, homossexuais, crianças, idosos, etc.), na possibilidade de ensinar os outros a tratar o nosso semelhante como um de nós, portanto, engajado na perspectiva da educação como mudança de atitude, de comportamento e de ideais de vida, é que poderemos criar uma sociedade mais justa, mais igualitária e eticamente possível. Pensar na igualdade que une os sujeitos pode não ser uma tarefa fácil, mas acreditamos ser esse um trabalho possível, na conquista e na primazia dos direitos humanos para as próximas décadas.

\section{Sergio Gomes da Silva}

Doutorando do Programa de Pós-Graduação em Psicologia Clínica pela Pontifícia Universidade Católica do Rio de Janeiro, RJ - Brasil.

Endereço para envio de correspondência:

Instituto de Psicologia - Divisão de Psicologia Aplicada Profa. Isabel Adrados - Av. Pasteur, 250 - Botafogo - Rio de Janeiro, RJ - Brasil - CEP 22290-240.

E-mail: sergiogsilva@uol.com.br 


\section{Referências}

Adelman, M. (2000). Paradoxos da identidade: a política de orientação sexual no século XX. Revista de Sociologia e Política, (14), 163-171.

Anistia Internacional. (2009). Por trás do silêncio - experiências de mulheres com a violência urbana no Brasil. Brasil: Autor.

Aragão, S. (2001). A vitimização da mulher. In C. B. Leal \& H. Piedade Júnior, Violência e vitimização: a face sombria do cotidiano (pp. 239-247). Belo Horizonte: Del Rei.

Bandeira, L., \& Batista, A. S. (2002). Preconceito e discriminação como expressões de violência. Revista Estudos Feministas, 10(1), 119-120.

Birman, J. (2001). Gramáticas do erotismo: a feminilidade e suas formas de subjetivação na psicanálise. Rio de Janeiro: Civilização Brasileira.

Brasil. (2002). Direitos Humanos - 1995-2002: políticas públicas de promoção e proteção. Brasília, DF: Secretaria de Estado dos Direitos Humanos.

Brasil. (2003). Direitos humanos: atualização do debate. Braślia, DF: Ministério das Relações Exteriores.

Brasil. (2007). Enfrentamento à violência contra a mulher: balanço de ações 2006-2007. Brasília, DF: Secretaria Especial de Políticas para as Mulheres.

Chauí, M. (1996/1997). Senso comum e transparência. In J. Lerner (Org.), O preconceito (pp. 115-132). São Paulo: Imprensa Oficial do Estado.

Dimenstein, G. (1996). Democracia em pedaços: direitos humanos no Brasil. São Paulo: Cia das Letras.

Dines, A. (1996/1997). Mídia, civilidade, civismo. In J. Lerner, J. (Org.), O preconceito (pp. 36-46). São Paulo: Imprensa Oficial do Estado.

Figueiredo, C. (1999). Gênero e cidadania: os direitos humanos no 3o milênio. Revista Direitos Humanos Gajop, (edição especial), 76-88.

Fraser, N. (2001). Da redistribuição ao reconhecimento? Dilemas da justiça na era pós-socialista. In J. Souza (Org.), Democracia hoje: novos desafios para a teoria democrática contemporânea (pp. 245282). Brasília, DF: Ed. da UNB.

Fraser, N. (2007). Mapeando a imaginação feminista: da redistribuição ao reconhecimento e à representação. Revista Estudos Feministas, 15(2), 291-308.

Giddens, A. (1993). A transformação da intimidade: sexualidade, amor e erotismo nas sociedades modernas. São Paulo: UNESP.

Gomes, R., Minayo, M. C. de S., \& Silva, C. F. R. (2005). Violência contra a mulher: uma questão transnacional e transcultural das relações de gênero. In Secretaria de Vigilância em Saúde, Impacto da violência na saúde dos brasileiros (pp. 117-140). Brasília, DF: Ministério da Saúde.
Heilborn, M. L. (2000). Violência e mulher. In G. Velho \& M. Alviti, Cidadania e violência (pp. 90-99). Rio de Janeiro: Ed. da UFPRJ.

Instituto de Segurança Pública do Rio de Janeiro. (2009). Dossiê Mulher (Vol. 2, 4a ed.). Rio de Janeiro: Autor. (Série Estudos). Recuperado em 05 de maio de 2009, de http://www.isp.ri.gov.br

Lasch, C. (1999). A mulher e a vida cotidiana: amor, casamento e feminismo. Rio de Janeiro: Civilização Brasileira.

Louro, G. L. (1997). Gênero, sexualidade e educação: uma perspectiva pós-estruturalista. Petrópolis, RJ: Vozes.

Machado, L. Z. (1998). Matar e morrer no feminino e no masculino. In D. Oliveira, E. C. Geraldes \& R. B. Lima, Primavera já partiu: retratos de homicídios femininos no Brasil (pp. 96-121). Petrópolis, RJ: Vozes.

Perlongher, N. (1993). Antropologia das sociedades complexas: identidade e territorialidade, ou como estava vestida Margaret Mead. Revista Brasileira de Ciências Sociais, 8(22), 137-144.

Pitanguy, J. (2003). Gênero, cidadania e direitos humanos. In C. Bruschini \& S. G. Unbehaum (Orgs.), Gênero, democracia e sociedade brasileira (pp. 109-119). São Paulo: Ed. 34.

Portella, A. P. (2006). Novas faces de violência contra as mulheres. In Marcadas a ferro. Brasília, DF: Secretaria Especial de Políticas Públicas para as Mulheres.

Rede Social de Justiça e Direitos Humanos. (2002). Direitos Humanos no Brasil 2002. Relatório da Rede Social de Justiça e Direitos Humanos. São Paulo: Autor.

Saffioti, H. I. B. (1989). A síndrome do pequeno poder. In M. A. Azevedo \& V. N. A. Guerra, (Orgs.), Crianças vítimizadas: a síndrome do pequeno poder (pp. 13-21). São Paulo: Iglu.

Scott, J. W. (1990). Gênero: uma categoria útil para análise histórica. Educação e Realidade, 16(2), 5-22.

Secretaria Especial de Políticas para as Mulheres. (2008). II Plano Nacional de Políticas para as Mulheres. Braślia, DF: Presidência da República.

Sennet, R. (2001). A corrosão do caráter. Rio de Janeiro: Record.

Silveira, M. L. (1997). Contribuições da perspectiva de gênero para o esboço de alternativas emancipatórias da sociedade. In Cidadania e subjetividade: novos contornos e múltiplos sujeitos (pp. 161-177). São Paulo: Imaginário.

Souza, C. M., \& Adesse, L. (2005). Violência sexual no Brasil: perspectivas e desafios. Brasília, DF: Secretaria Especial de Políticas para as Mulheres.

Unifem. (2009). Progresso das Mulheres no Mundo 2008/2009 - Quem responde às mulheres: gênero e responsabilização. Recuperado em 05 de maio de 2009, de http://www.unifem.org. br/sites/700/710/00000395.pdf 